\title{
EFFECT OF AGING TREATMENT ON PITTING CORROSION AND CORROSION FATIGUE CRACK PROPAGATION BEHAVIOR OF OIL-GRADE ALLOY 718
}

\author{
Jared S. Nutter ${ }^{1,2,3}$, Ting Chen ${ }^{1,2}$, Jeffrey Hawk ${ }^{1}$, Xingbo Liu ${ }^{1,2}$ \\ ${ }^{1}$ National Energy Technology Laboratory; \\ Albany, OR 97321-2198, USA \\ ${ }^{2}$ Department of Mechanical and Aerospace Engineering; West Virginia University; \\ Morgantown, WV 26506, USA \\ ${ }^{3}$ Belcan Corporation; \\ Cincinnati, $\mathrm{OH} 45242$, USA
}

Keywords: Oil-grade alloy 718, Aging treatment, Pitting corrosion, Corrosion fatigue crack propagation

\begin{abstract}
In this study, the influence of aging treatment on pitting corrosion and corrosion fatigue crack propagation (CFCP) behavior of oil-grade alloy 718 in different $\mathrm{NaCl}$ solutions is investigated. Electrochemical measurement results show no change in the pitting corrosion resistance of alloy 718 , regardless of aging treatment, indicated by the similar corrosion current density and pitting potential. The pitting corrosion resistance is decreased with the increase in solution temperature and $\mathrm{NaCl}$ concentration. $\mathrm{CFCP}$ results demonstrate that there is no effect of $3.5 \mathrm{wt} \% \mathrm{NaCl}$ solution on the CFCP rates of alloy 718 in comparison with the ones tested in air, in spite of aging treatment. Nevertheless, 21 wt. \% $\mathrm{NaCl}$ solution produces a deleterious effect on the CFCP rates of alloy 718. Aging treatments lead to lower CFCP rates in all tested environments. However, no difference of CFCP rates is observed between one-step aged and two-step aged specimens.
\end{abstract}

\section{Introduction}

Nickel-base alloy 718 was originally developed for use in high temperature, aircraft gas turbine engines. It was first used in the oil and gas industry for fasteners, valve stems, shafts, and drill tools (applications that only involve brief exposure to corrosive conditions). By the 1980s, alloy 718 began to be used in critical well completion equipment such as hangers, packers, and subsurface safety valves. Recently, the largest use of alloy 718 is for downhole tools such as subsurface safety valves, packers, flow control devices, and other tools. Wellhead distribution equipment may also be made of high-strength, nickel-base alloys. These components reduce pressure through a complex system of valves and combine or distribute the oil and or gas flow. In the case of offshore wells, these devices sit on the ocean floor, exposing them to long term sea water environments. Alloy 718 has also been used in downhole measurement tools including devices such as logging-while-drilling (LWD) and measurement-while-drilling (MWD), where sophisticated electronic instruments are contained in a strong, nonmagnetic alloy tube [1-7].

It is well known that nickel-base alloy 718 can be age hardened to various strength levels by adjusting the heat treatment procedures. Oil-grade alloy 718 is solution annealed at a temperature of $1021^{\circ} \mathrm{C}$ to $1052^{\circ} \mathrm{C}$ for one to two and a half hours, followed by the single-step aging treatment 
at $774^{\circ} \mathrm{C}$ to $802^{\circ} \mathrm{C}$ for six to eight hours [1,9]. This single-step aging treatment is described in API standard 6A718 specified for nickel-base alloy 718 used in oil and gas drilling and production to increase stress corrosion cracking (SCC) and sulfide stress cracking (SSC) resistance [10]. This is achieved by sacrificing mechanical properties such as yield strength and hardness. Since the demand of strength and toughness increases in deep well drilling, a two-step aging treatment at $760{ }^{\circ} \mathrm{C}$ and $650{ }^{\circ} \mathrm{C}$ has been adopted for oil-grade alloy 718 in recent years to maximize the mechanical properties $[2,11]$. However, there has been no research into the corrosion fatigue properties of this new aging treatment or the standard aging treatment in low temperature aqueous $\mathrm{NaCl}$ environments. Thus, it is important to investigate whether this aging treatment affects the pitting corrosion and corrosion fatigue resistance of oil-grade alloy 718 since the mechanical properties have been improved.

This study investigated the influence of aging treatment on pitting corrosion and corrosion fatigue crack propagation behavior of oil-grade alloy 718 in $\mathrm{NaCl}$ solution. The effects of solution temperature, cyclic waveform, and chloride concentration were also studied.

\section{Experimental Procedure}

The microstructure of all three specimens was examined by means of optical microscope (OM) and scanning electron microscope (SEM). The specimens mounted in epoxy were mechanically ground by 120-1200 grit silicon carbide waterproof papers and polished with $3 \mu \mathrm{m}$ and $1 \mu \mathrm{m}$ diamond suspension, followed by a $4 \mathrm{~min}$ chemical etching with Kalling's solution which consisted of $200 \mathrm{ml}$ methanol, $200 \mathrm{ml}$ hydrochloric acid and $10 \mathrm{~g} \mathrm{CuCl}_{2}$. A JEOL JSM-7600F SEM equipped with an Oxford Inca energy-dispersive X-ray spectrometry (EDS) system was used to examine the microstructure and phases in these specimens.

Electrochemical polarization characteristics were obtained for samples with an exposed area of 1 $\mathrm{cm}^{2}$ (after epoxy mounting) in a $1.5 \mathrm{~L}$ glass cell with the different sodium chloride $(\mathrm{NaCl})$ solutions and temperatures. A three-electrode cell setup was used consisting of the specimen as the working electrode, a pair of graphite counter electrodes, and an $\mathrm{Ag} / \mathrm{AgCl}$ reference electrode immersed in a saturated potassium chloride $(\mathrm{KCl})$ solution. Electrochemical measurements were recorded using a Solartron SI 1287 electrochemical interface with a scan rate of $0.5 \mathrm{mV} / \mathrm{s}$. Each test was conducted at least three times then averaged.

Corrosion fatigue crack propagation (CFCP) tests were performed using single-edge-notched (SEN) tensile specimens of oil-grade alloy 718 with the chemical composition listed in Table 1. The single-edge-notched specimens with notch length of $3.81 \mathrm{~mm}$ were machined and polished to a 600 -grit finish. Three different aging treatments including un-aged, one-step aged, and twostep aged were investigated with the name and details listed in Table 2.

Table 1. Chemical composition (wt\%) of oil-grade alloy 718 .

\begin{tabular}{|c|c|c|c|c|c|c|c|c|c|c|c|c|c|c|c|c|}
\hline $\mathbf{N i}$ & $\mathbf{C r}$ & $\mathbf{F e}$ & $\mathbf{M o}$ & $\mathbf{N b}$ & $\mathbf{A l}$ & $\mathbf{T i}$ & $\mathbf{M n}$ & $\mathbf{S i}$ & $\mathbf{C}$ & $\mathbf{C o}$ & $\mathbf{C u}$ & $\mathbf{T a}$ & $\mathbf{P}$ & $\mathbf{S}$ & $\mathbf{B}$ & $\mathbf{P b}$ \\
\hline 52.66 & 18.34 & 19.18 & 3.00 & 4.96 & 0.49 & 0.95 & 0.05 & 0.06 & 0.03 & 0.04 & 0.04 & 0.01 & 0.006 & 0.001 & 0.003 & 0.0002 \\
\hline
\end{tabular}


Table 2. Heat treatment details.

\begin{tabular}{|c|c|c|c|}
\hline Specimen & Soln. Annealing & Aging Treatment & Details \\
\hline 0 & $1026^{\circ} \mathrm{C}, 1.5 \mathrm{hrs} / \mathrm{WQ}$ & No Aging & N/A \\
1 & $1026^{\circ} \mathrm{C}, 1.5 \mathrm{hrs} / \mathrm{WQ}$ & One-Step Aging & $780^{\circ} \mathrm{C}, 8 \mathrm{hrs}$. \\
2 & $1026^{\circ} \mathrm{C}, 1.5 \mathrm{hrs} / \mathrm{WQ}$ & Two-Step Aging & $780^{\circ} \mathrm{C}, 4.5 \mathrm{hrs} .+650^{\circ} \mathrm{C}, 5 \mathrm{hrs}$. \\
\hline
\end{tabular}

Fatigue tests were carried out to a crack length of approximately $10 \mathrm{~mm}$ using a servo-hydraulic fatigue test stand manufactured by MTS. Specimens were pre-cracked in air to an estimated crack length of $4.5 \mathrm{~mm}$ using a triangle waveform loading cycle at a frequency $(f)$ of $10 \mathrm{~Hz}$ prior to crack propagation testing. Two different fatigue waveforms were used, trapezoidal and triangular. The triangle waveform consisted of constant loading at a frequency of $1 \mathrm{~Hz}$ in 3.5 wt. $\% \mathrm{NaCl}$ at RT, $50^{\circ} \mathrm{C}$, and $80^{\circ} \mathrm{C}$. The trapezoidal waveform involved a 0.5 second linear ramp up to maximum load, 29 second hold at maximum load and 0.5 second linear ramp down to minimum load hold-time waveform in $3.5 \mathrm{wt} \% \mathrm{NaCl}$ at $80^{\circ} \mathrm{C}$. Hold-time was only tested at $80^{\circ} \mathrm{C}$ solution temperature because the corrosion container was limited to ambient pressures, and the lower temperatures would only lesson the corrosion effect of the solution. Both cycles, as well as the pre-crack cycle, used the same constant loading of a minimum of $890 \mathrm{~N}$ and a maximum of $8896 \mathrm{~N}$. A potential drop method was utilized to monitor the crack length with an applied constant current of $10 \mathrm{~A}$. The voltage was measured and recorded by a strain gage input channel connected to the MTS controller with a resolution of one microvolt. Data points were recorded based on time since the cycles were also time dependent. Trapezoidal waveform potentials were recorded every 0.5 second, $1 \mathrm{~Hz}$ triangle wave potentials were recorded every 0.5 second, and pre-crack data was recorded every 1 second. For CFCP tests, $3.5 \mathrm{wt} \% \mathrm{NaCl}$ and 21 wt. $\% \mathrm{NaCl}$ aqueous solutions were used.

A custom container was designed to submerge the specimen crack in the corrosive solution during fatigue testing. Aluminum 5052 was selected for the building material due to its good resistance to corrosion and low weight. Weight was considered because the container was mounted freely to the specimen so it could move with the cycle movement without impeding on the specimen's freedom of movement along the loading axes. The specimen passed through the middle of the container using rubber corks on the top and bottom sealed by two different kinds of silicon sealant. The sealant, not submerged in solution on the top, was household silicon that was easier to work with, and the bottom sealant was an automotive gasket sealant that was corrosion resistant. It was heated to the desired temperature using a single resistant heating rope controlled by an auto tuned programmable temperature controller. The temperature was monitored near the crack tip with a T-type thermocouple implementing an Inconel sheath material to protect it from the corrosive environment. Wires were passed in and out of the container through holes in the acrylic lid sealed by the household silicon to monitor the potential drop of the crack growth.

A MATLAB program was written to calculate the change in crack length and stress intensity factor difference from the voltage data using the potential drop method. The noise was removed by defining the raw voltage as an array and running it through a loop that defined a new max voltage array with a progressing maximum creating voltage steps. This method is based on the assumption that the crack cannot reduce its' length and therefore the voltage can only grow in magnitude, making all voltage below the current maximum irrelevant for crack growth. Using the new maximum voltage array, the crack length was calculated with Equation 1 [12]. 


$$
a=\frac{y}{\phi} \cos ^{-1}\left[\frac{\cosh (\phi)}{\cosh \left\{\frac{u}{u_{0}} \cosh ^{-1}\left(\frac{\cosh (\phi)}{\cos \left(\phi a_{0} y^{-1}\right)}\right)\right)}\right]
$$

where $a_{0}$ is the initial crack length, $w$ is the specimen width of $19.05 \mathrm{~mm}, y$ is the half potential probe span, $u_{0}$ is the initial measure potential drop, and $u$ is the current measure potential drop. The stress intensity factor for this specimen geometry was calculated with Equation 2 [12].

$$
\begin{gathered}
K=\frac{p}{t \sqrt{w}} \frac{\sqrt{2 \tan \theta}}{\cos \theta}\left[0.752+2.02\left(\frac{a}{w}\right)+0.371(1-\sin \theta)^{3}\right] \\
\text { where, } \theta=\frac{\pi a}{2 w}
\end{gathered}
$$

where $t$ is the specimen thickness of $3.175 \mathrm{~mm}$ and $p$ is the applied load. The final data points for plotting crack growth rates were produced by averaging $d a / d N$ based on $\Delta K$, which was necessary due to the large amount of zero crack growth the voltage steps create.

\section{Results}

\section{Microstructure}

Figures 1 and 2 show the typical microstructure of the three specimens obtained from optical microscopy (OM) and scanning electron microscopy (SEM). Based on the criteria in API specification 6A718, both aged specimens were judged to be acceptable for oil-grade alloy 718 . After solution heat treatment, the average grain size of Specimen 0 is $46 \mu \mathrm{m}$. The average grain size of Specimen 1 is $52 \mu \mathrm{m}$ and Specimen 2 is $60 \mu \mathrm{m}$. Neither Laves phases nor acicular delta phases are present in the matrix, but there is an acceptable amount of globular delta phases.

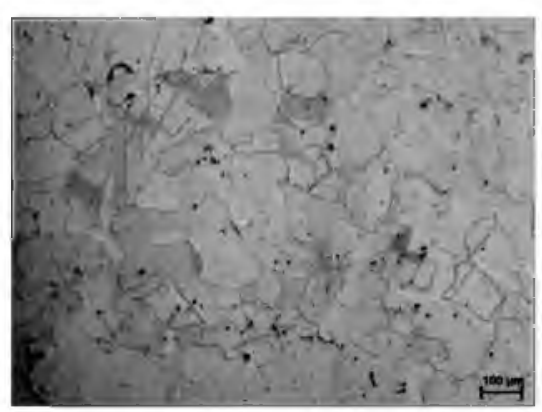

(a)

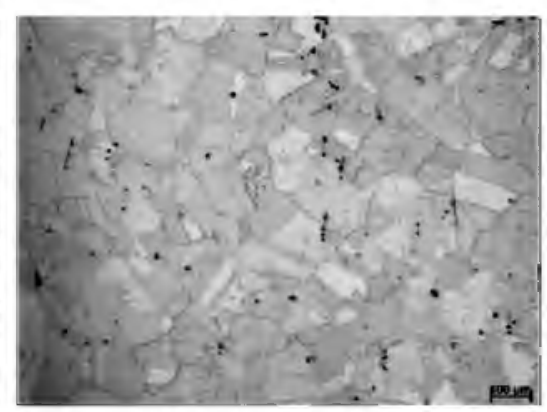

(b)

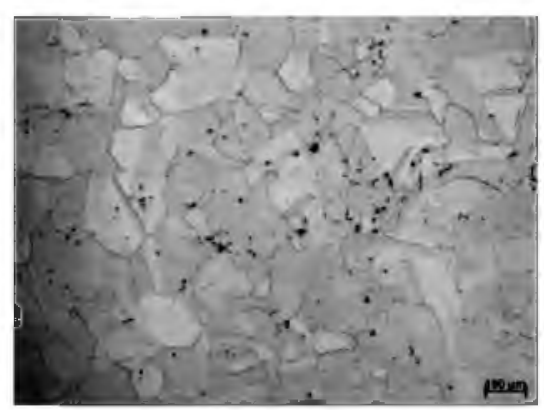

(c)

Figure 1. Optical micrographs of three oil-grade alloy 718 specimens: (a) Specimen 0, (b) Specimen 1, (c) Specimen 2. 


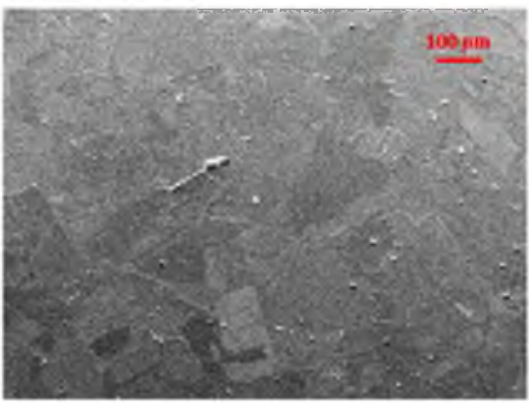

(a)

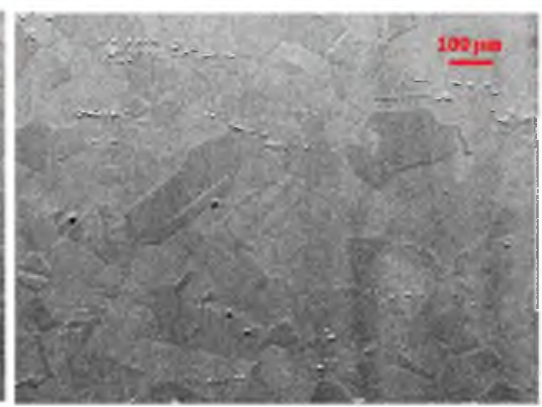

(b)

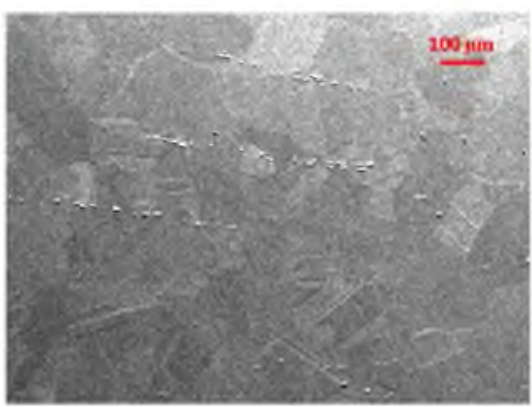

(c)

Figure 2. SEM images of three oil-grade alloy 718 specimens: (a) Specimen 0,

(b) Specimen 1, (c) Specimen 2.

Detailed analysis of Specimen 0 indicated that carbides and nitrides are both distributed along the grain boundaries and within the grains. EDS analysis verified that the big globular particles are $(\mathrm{Nb}, \mathrm{Ti}) \mathrm{C}$ carbides and the rectangular shaped inclusions are $(\mathrm{Ti}, \mathrm{Nb}) \mathrm{N}$ nitrides. For Sample 1 , along with $(\mathrm{Nb}, \mathrm{Ti}) \mathrm{C}$ and $(\mathrm{Ti}, \mathrm{Nb}) \mathrm{N}$ particles along the grain boundaries and within the grain matrix, similar to that of Sample 0, isolated platelet $\delta$ phase was precipitated at some of the grain boundaries, as revealed in Figure 3 (a). A depletion of precipitates is observed surrounding the grain boundaries due to the formation of $\delta$ phase, and a uniform distribution of very fine spherical and elongated precipitates within the grains. From transmission electron microscopy (TEM) analysis, spherical $\gamma^{\prime}$ precipitates are approximately in 20-30 nm diameter while the $\gamma^{\prime \prime}$ disks are 5-15 $\mathrm{nm}$ in the c dimension and the diameter is in the range of 30-150 $\mathrm{nm}$. Shown in Figure 3 (b), in Sample 2, the $\gamma^{\prime}$ is in global shape with a size of 5-15 nm and the $\gamma^{\prime \prime}$ is in disc shape with a diameter of $10-30 \mathrm{~nm}$, which are much smaller than the ones formed during the one-step aging treatment.

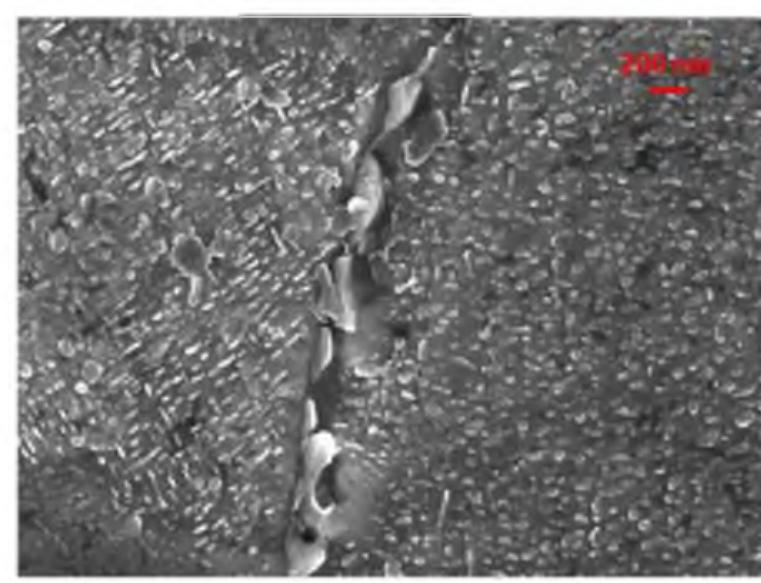

(a) - Sample 1

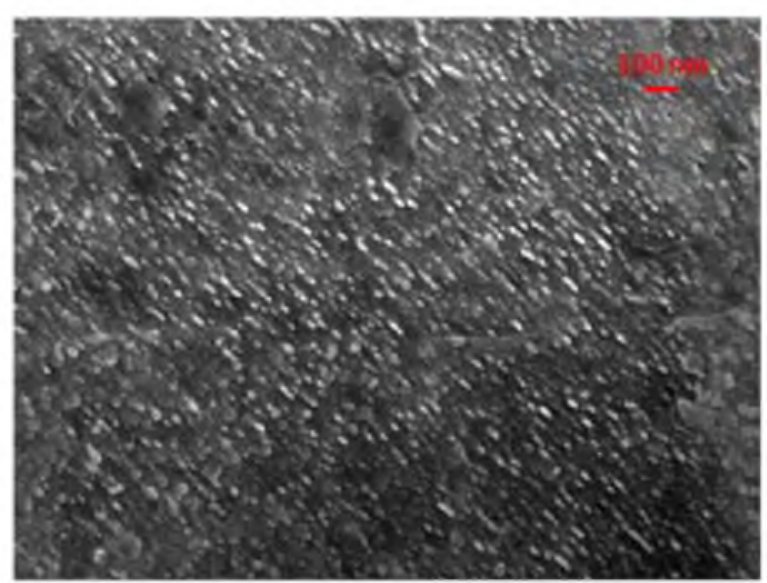

(b) - Sample 2

Figure 3. SEM images of (a) Specimen 1 and (b) Sample 2, showing grain boundary $\delta$ phase and $\gamma$ '\& $\gamma^{\prime \prime}$ precipitates. 

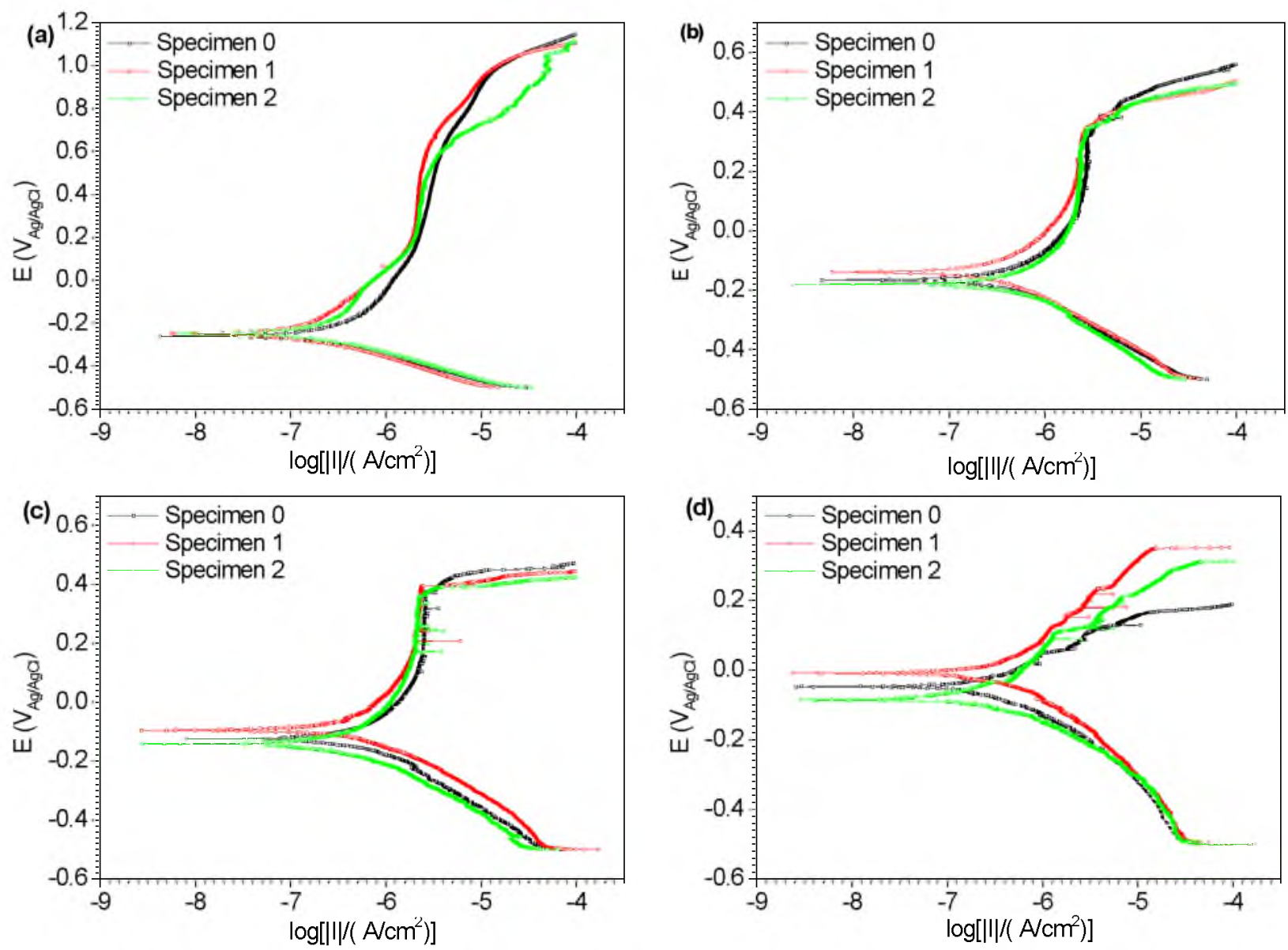

Figure 4. Potentiodynamic polarization curves of oil-grade alloy 718 in four different $\mathrm{NaCl}$ solutions: (a) $3.5 \mathrm{wt} . \% \mathrm{NaCl}$ at RT, (b) $3.5 \mathrm{wt} \% \mathrm{NaCl}$ at $50^{\circ} \mathrm{C}$, (c) $3.5 \mathrm{wt} . \% \mathrm{NaCl}$ at $80^{\circ} \mathrm{C}$, (d) 21 wt. $\% \mathrm{NaCl}$ at $80^{\circ} \mathrm{C}$.

Potentiodynamic Polarization

Figure 4 illustrates the effect of aging treatment on potentiodynamic polarization curves measured in four different aerated $\mathrm{NaCl}$ solutions. It can be observed that aging treatment has no noticeable effect on the polarization characteristics for oil-grade alloy 718 in all testing environments. This indicates that alloy 718 with different aging treatments has similar susceptibility to pitting corrosion in the subject $\mathrm{NaCl}$ solutions. 

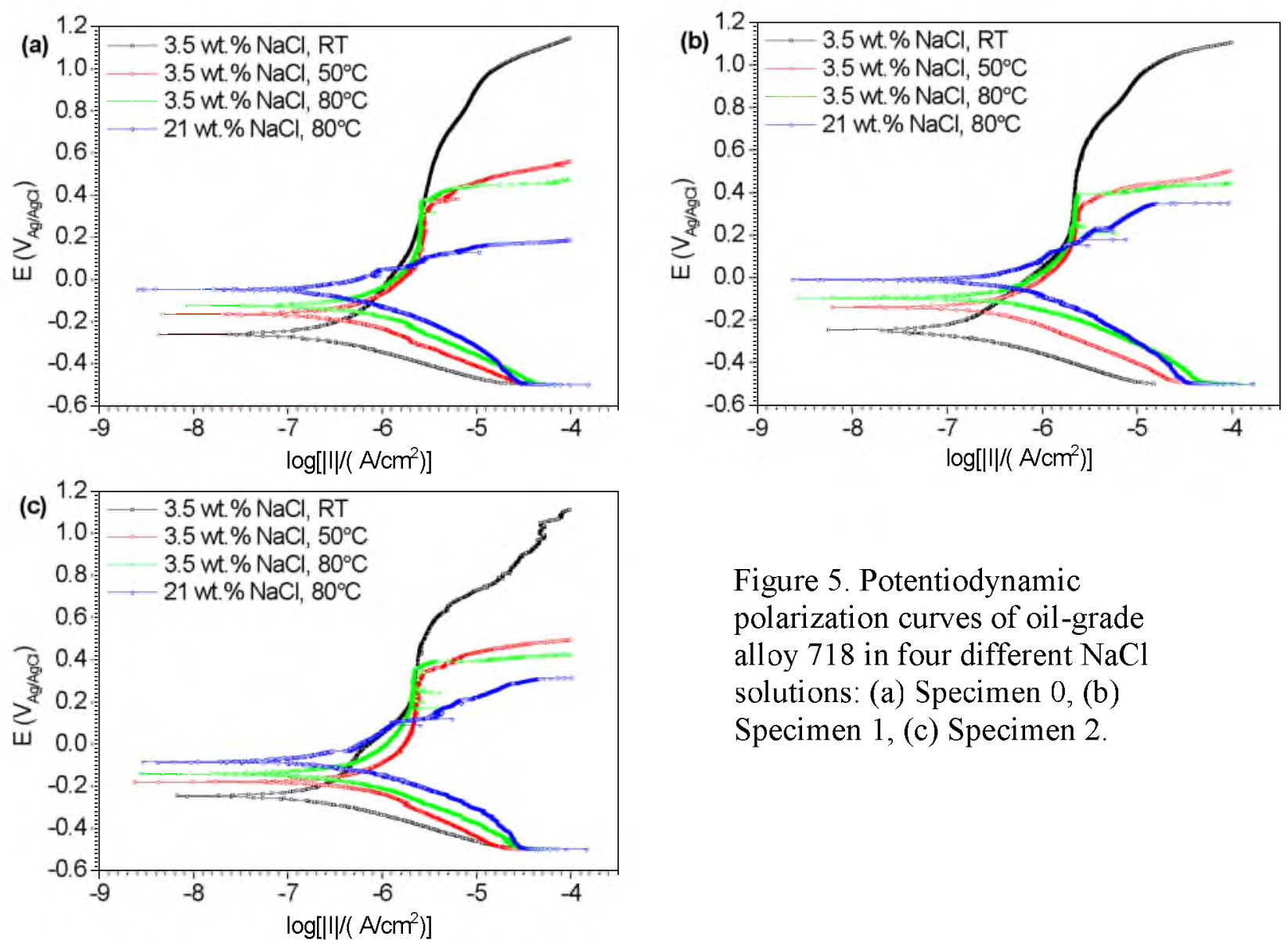

Figure 5. Potentiodynamic polarization curves of oil-grade alloy 718 in four different $\mathrm{NaCl}$ solutions: (a) Specimen 0, (b) Specimen 1, (c) Specimen 2.

Figure 5 compares the influence of different aerated $\mathrm{NaCl}$ solutions on potentiodynamic polarization curves for the three alloy 718 aging treatments. The active, passive, and transpassive regions can be seen clearly in the potentiodynamic polarization curves measured in 3.5 wt. $\% \mathrm{NaCl}$ solution at three different temperatures, demonstrating that alloy 718 exhibits passive behavior in these corrosive environments. However, the electrochemical behavior of oil-grade alloy 718 in 21 wt. $\% \mathrm{NaCl}$ solution at $80^{\circ} \mathrm{C}$ is quite different. The anodic current is observed to continue rising with increasing potential, and there is no clear passive range that can be defined in the potentiodynamic polarization curves obtained in $21 \mathrm{wt} \% \mathrm{NaCl}$ solution at $80^{\circ} \mathrm{C}$ for all samples. This indicates that the metal dissolution behavior of the alloys in this environment is active corrosion. By using the results of $3.5 \mathrm{wt} . \% \mathrm{NaCl}$ solution at $\mathrm{RT}$ as the baseline data for comparison, it is observed that pitting potential $\left(E_{\text {pit }}\right)$ decreases with an increase in temperature of $3.5 \mathrm{wt} . \% \mathrm{NaCl}$ solution from $\mathrm{RT}$ to $80^{\circ} \mathrm{C}$. These comparisons demonstrate that alloy 718 is more susceptible to pitting corrosion in $3.5 \mathrm{wt} \% \mathrm{NaCl}$ solution with a higher temperature. In addition, with an increase in the $\mathrm{NaCl}$ concentration in the corrosive solution at $80^{\circ} \mathrm{C}$, the passive region was eliminated. This is likely due to the presence of a high concentration of $\mathrm{Cl}^{-}$, leading to the increased break down of the porous passive films. 


\section{Corrosion Fatigue Crack Propagation}

The CFCP rate of Specimens 0,1 , and 2 in air, $3.5 \mathrm{wt} . \% \mathrm{NaCl}$ at room temperature (RT), $50^{\circ} \mathrm{C}$, $80^{\circ} \mathrm{C}$, and 21 wt. $\% \mathrm{NaCl}$ at $80^{\circ} \mathrm{C}$ are shown in Figure 6. In Figure 6 (a), it appears that there is no effect of the salt solution at any temperature on the crack growth rate for Specimen 0. This trend continues for Specimens 1 and 2 where there is not a clear increase in CFCP rate in Figure 6 for tests in $3.5 \mathrm{wt} \% \mathrm{NaCl}$ solution or increased solution temperature compared with air. However, when a curve fit is calculated for the most stable portion of the tests ( $\Delta \mathrm{K}$ values between 25 and 45 ) the results appear to become more defined. Figure 7 shows the curve fit data for Specimens 0, 1 , and 2 in air, $3.5 \mathrm{wt} . \% \mathrm{NaCl}$ at RT, $50^{\circ} \mathrm{C}, 80^{\circ} \mathrm{C}$, and $21 \mathrm{wt} . \% \mathrm{NaCl}$ at $80^{\circ} \mathrm{C}$. At $\Delta \mathrm{K}$ values less than 30 , there is an increase in crack growth rate in $3.5 \mathrm{wt} . \% \mathrm{NaCl}$ solution compared to air for all three specimens. As $\Delta \mathrm{K}$ increases, the difference in crack growth rate decreases, implying that the mechanical effects of fatigue are becoming more dominate than the corrosiveness of the salt solution. When Figures 6 and 7 are compared, the increase in Figure 7 does not completely match the trend in Figure 6. This implies that there is not an increase in crack growth rate but rather an increased instability in the crack growth rate in $3.5 \mathrm{wt} . \% \mathrm{NaCl}$ when compared to air. Also, Figure 7 shows that salt solution temperature up to $80^{\circ} \mathrm{C}$ has no effect on CFCP rate.
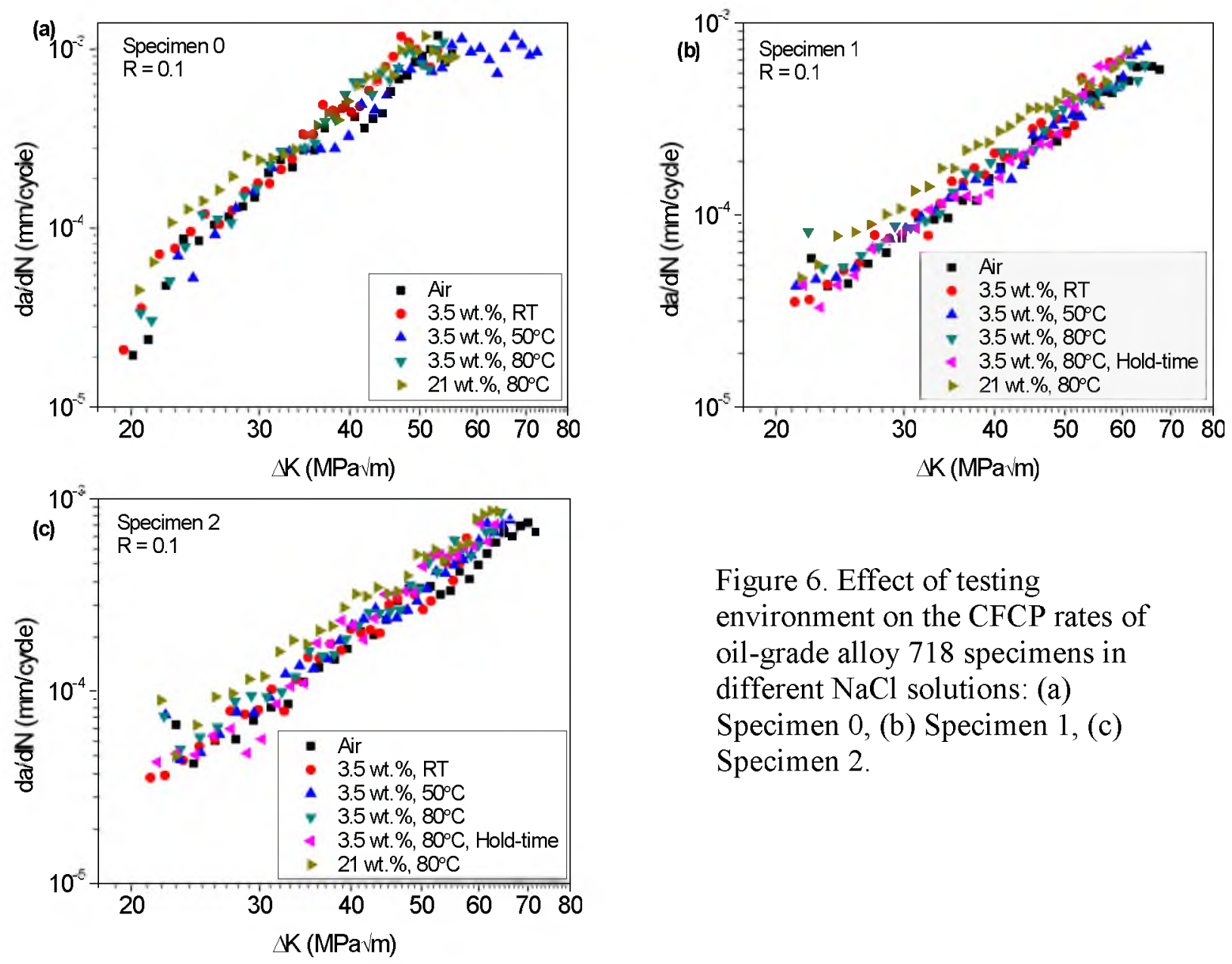

Figure 6. Effect of testing environment on the CFCP rates of oil-grade alloy 718 specimens in different $\mathrm{NaCl}$ solutions: (a) Specimen 0, (b) Specimen 1, (c) Specimen 2. 
To investigate the effect of triangular and trapezoidal waveforms on crack growth rate, a trapezoidal waveform was used with a 29 second hold-time and 0.5 second linear loading and unloading in $80^{\circ} \mathrm{C}$ solution temperature. The CFCP rates of Specimens 1 and 2 under trapezoidal and triangular waveforms in air at RT and $3.5 \mathrm{wt} . \% \mathrm{NaCl}$ at $80^{\circ} \mathrm{C}$ are shown in Figure 6. The $\mathrm{CFCP}$ rates in $\mathrm{NaCl}$ solution for all tested conditions are almost equal to the rate in air for the entire $\Delta \mathrm{K}$ range. Therefore, the hold-time of the trapezoidal waveform had no increased effect on the CFCP rate for the aged specimens from that of the triangular waveform tests. The curve fits in Figure 7 confirm this conclusion.
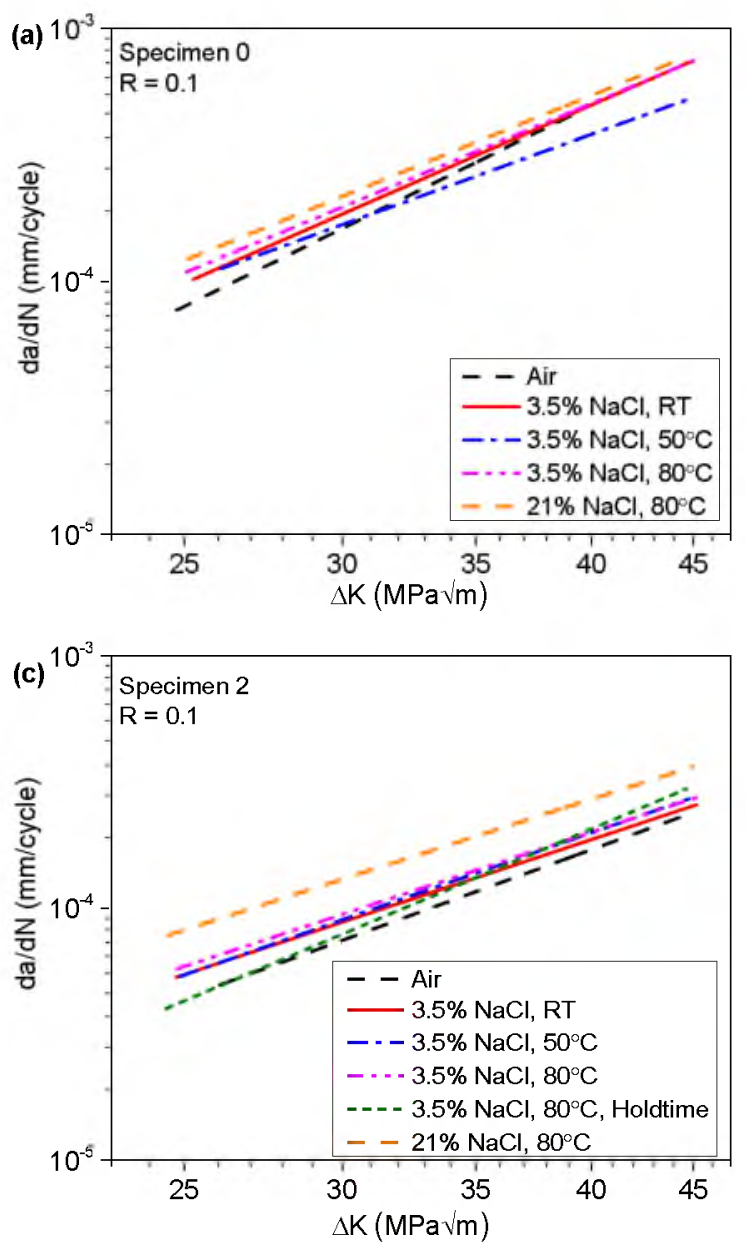

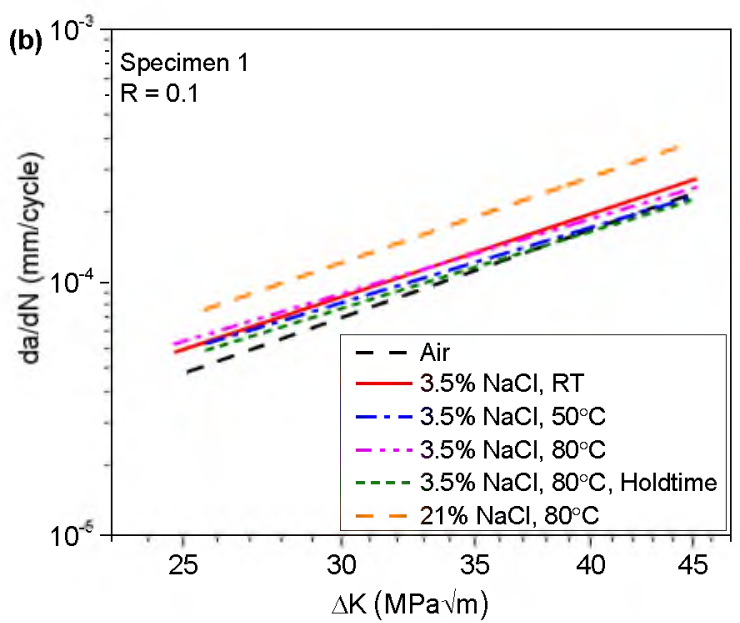

Figure 7. Curve fit of the effect of testing environment on the CFCP rates of oil-grade alloy 718 specimens in different $\mathrm{NaCl}$ solutions: (a) Specimen 0, (b) Specimen 1, (c) Specimen 2.

Increasing the concentration from 3.5 to $21 \mathrm{wt} . \% \mathrm{NaCl}$ produced the largest increase in crack growth rate shown in Figure 6. To examine this increase, the CFCP rate for Specimens 0, 1, and 2 in air, $3.5 \mathrm{wt} . \% \mathrm{NaCl}$, and $21 \mathrm{wt} \% \mathrm{NaCl}$ solution at $80^{\circ} \mathrm{C}$ are plotted in Figure 8 . There is a clear increase in crack growth rate for $21 \mathrm{wt} . \% \mathrm{NaCl}$ solution compared to both air and $3.5 \mathrm{wt} . \%$ salt solution. This indicates that the passivation film is more unstable and does not reform as quickly as in $3.5 \mathrm{wt} \% \mathrm{NaCl}$ solution. The reduction in repassivation rate allows for an increase in metal dissolution resulting in the increase in $\mathrm{CFCP}$ rate. Although there is also an increase in crack growth rate in Figure 8 (c) at low $\Delta \mathrm{K}$ values, the increase is not large enough to conclude that the $3.5 \mathrm{wt} . \% \mathrm{NaCl}$ solution caused the increase. From Figures 6 and 7 , the changes in crack growth rate from the different $3.5 \mathrm{wt} . \% \mathrm{NaCl}$ tests are all grouped together with the tests in air. 
Therefore, it is more likely that the effect of $3.5 \mathrm{wt} . \% \mathrm{NaCl}$ concentration is an instability in the CFCP rate rather than a definitive increase from tests in air. When the CFCP rates are compared between the aging treatments in Figure 8, the results show that the unaged Specimen A has a higher crack growth rate than the two aged specimens in all conditions. There is almost no difference between Specimen 1 and 2 in any condition.
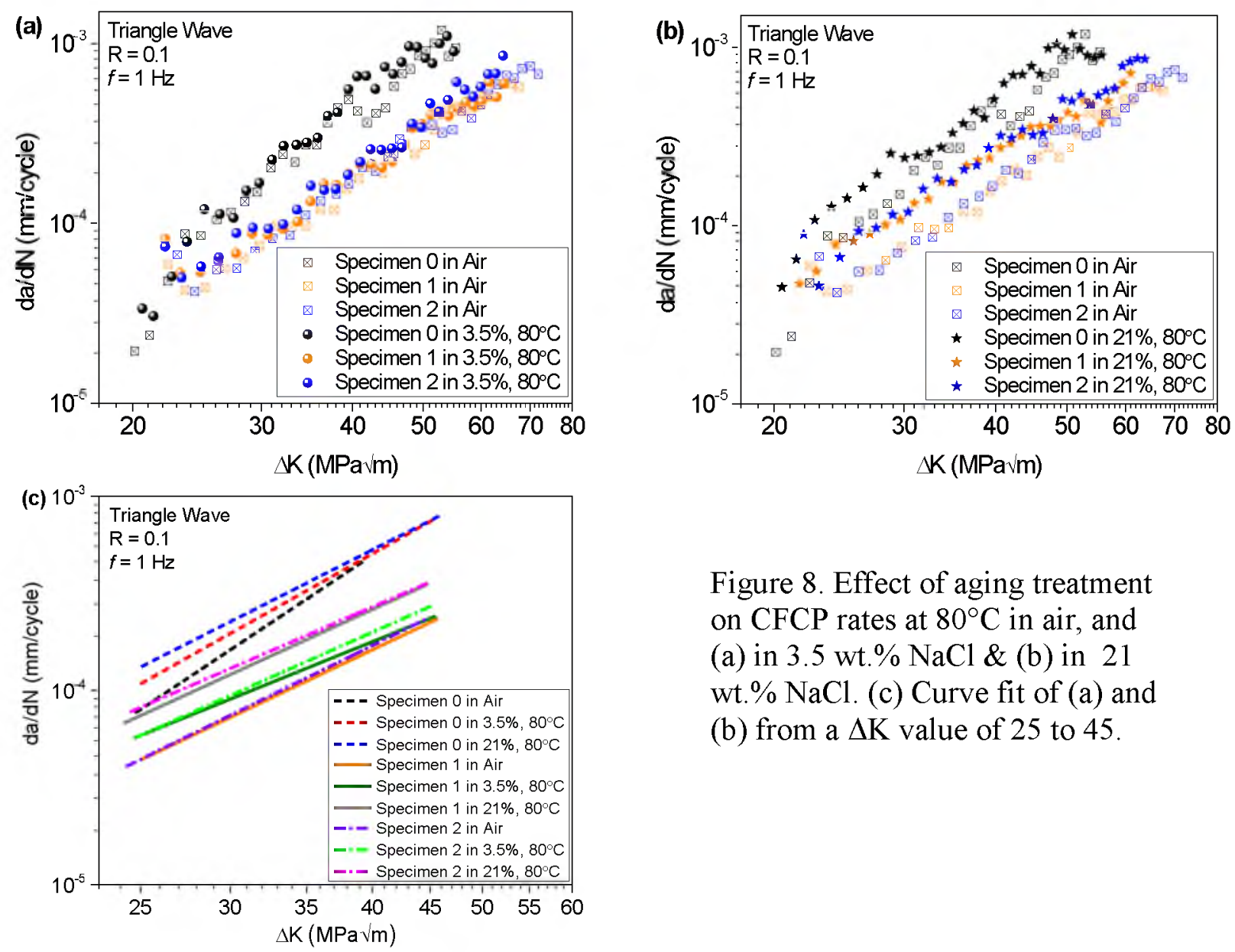

Figure 8. Effect of aging treatment on CFCP rates at $80^{\circ} \mathrm{C}$ in air, and (a) in $3.5 \mathrm{wt} \% \mathrm{NaCl} \&$ (b) in 21 wt. $\% \mathrm{NaCl}$. (c) Curve fit of (a) and (b) from a $\Delta \mathrm{K}$ value of 25 to 45.

The fracture surfaces of the three aging treatments in air are shown in Figure 9, and in 21 wt.\% $\mathrm{NaCl}$ solution at $80^{\circ} \mathrm{C}$ are shown in Figure 10 . In these figures, the top of the fracture surface correlates with the beginning of the crack (including pre-crack), and the crack propagated in the downward direction. As would be expected, Figure 9 shows no clear transition from pre-crack to FCP crack for the specimens in air. There are also no clear transitions for the specimens in 21 wt.\% $\mathrm{NaCl}$ solution shown in Figure 10. All of the fatigue cracks propagated in a transgranular fracture mode regardless of aging treatment or environment. This indicates that the grain boundaries are not important factors for CFCP. Also, there is a mix of brittle cleavage and ductile striations for all tested conditions, as well as, some secondary cracking. However, there are no clear differences on the fracture surfaces between the aging treatments or testing environments. 
(a)

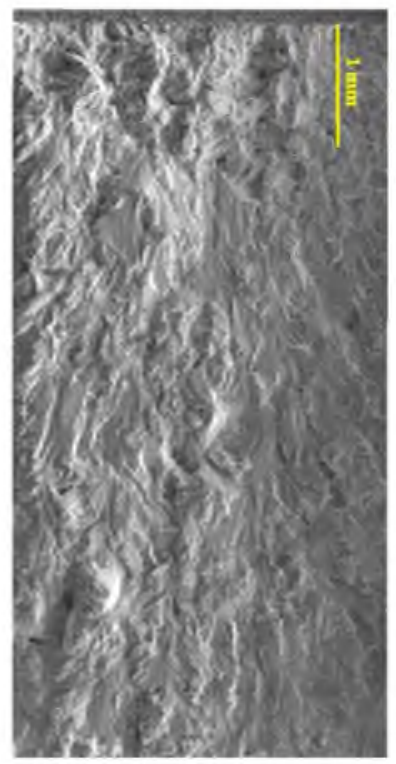

(b)

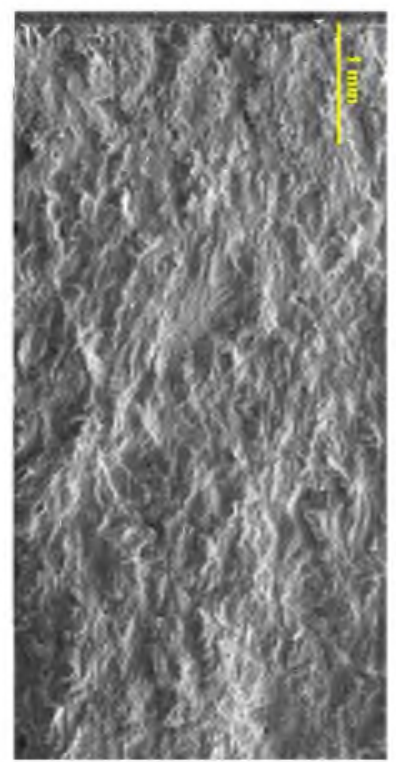

(c)

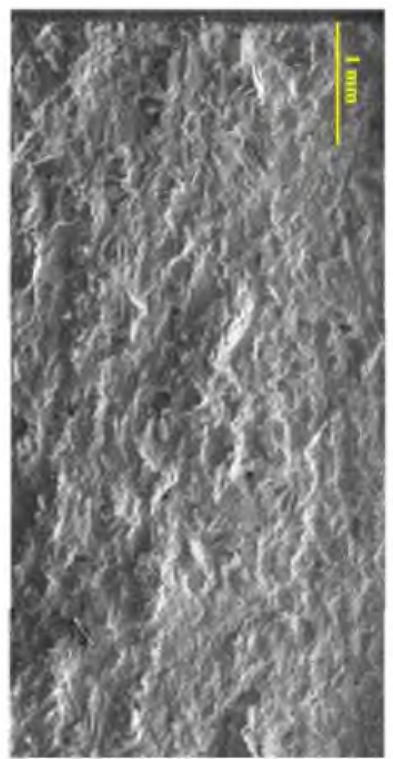

Figure 9. SEM images of the fracture surface of (a) Specimen 0, (b) Specimen 1, and (c) Specimen 2 in air at RT.

(a)

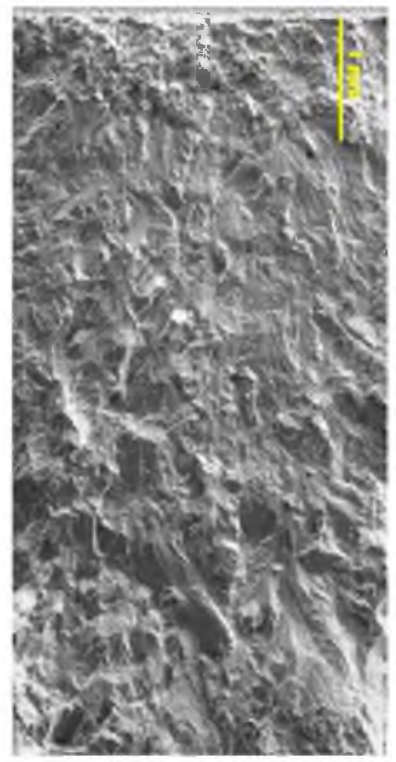

(b)

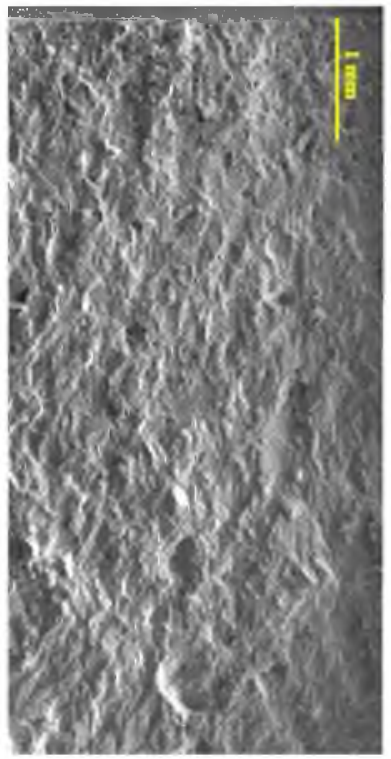

(c)

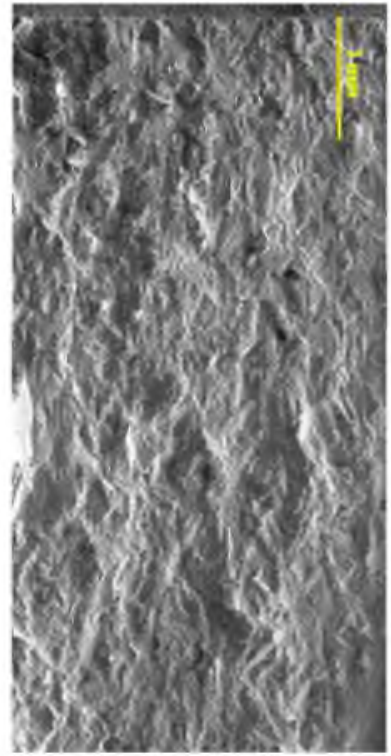

Figure 10. SEM images of the fracture surface of (a) Specimen 0, (b) Specimen 1, and (c) Specimen 2 in $21 \mathrm{wt} . \% \mathrm{NaCl}$ solution at $80^{\circ} \mathrm{C}$. 


\section{Discussion}

The effect of heat treatment in terms of microstructure and mechanical properties on FCP rates in alloy 718 has been extensively studied [13-21]. Tsay et al. [22] have investigated the FCP behavior of IN 718 plate and laser annealed specimens in air. Their results indicated that both solution-annealed and aged IN 718 specimens showed similar fatigue properties in air in the low $\Delta \mathrm{K}$ range, even though they had significant differences in tensile strength and impact toughness. They suggested that those fine precipitates formed during the aging treatment did not resist dislocation shearing, thereby had little influence on the retardation of crack growth. Moreover, the solution-annealed sample had higher FCP rates than the aged sample at the $\Delta \mathrm{K}>30 \mathrm{MPa} \sqrt{\mathrm{m}}$, while the laser-annealed specimen had higher FCP resistance than the bulk. Ghonem et al. [31, 32] has pointed out that microstructure factors including precipitate size, grain size, and morphology cause the degree of homogeneity of plastic deformation and associated slip density to become the influencing parameters at the crack tip, thus in turn greatly affecting the FCP rate. Published TEM results have shown that fine $\gamma$ " precipitates were sheared by dislocations, slip and twinning, which could hamper fatigue crack propagation [23-26]. The results of the present study confirm the advantage of $\gamma^{\prime} / \gamma^{\prime \prime}$ precipitate microstructure formed during both one-step and two-step aging treatments when compared to purely the $\gamma$ austenitic phase in terms of FCP. Therefore, the shearing mechanism of the $\gamma^{\prime} / \gamma^{\prime}$ precipitates caused the lower FCP rate of the aged alloy 718 specimens in air. The potentiodynamic polarization results show that the tested aging treatments have similar corrosion performance in $3.5 \mathrm{wt} . \% \mathrm{NaCl}$ solution at different temperatures. However, the three specimens still display similar CFCP rates in $3.5 \mathrm{wt} . \% \mathrm{NaCl}$ solution as in air. This shows that the CFCP mechanisms for the tested aging treatments for alloy 718 are dominated by the mechanical properties rather than the corrosion properties in $3.5 \mathrm{wt} \%$ $\mathrm{NaCl}$ up to $80^{\circ} \mathrm{C}$.

Wang et al. [27] investigated the influence of loading waveform on CFCP rates for iron in 3.5\% $\mathrm{NaCl}$ and $3.5 \% \mathrm{NaCl}+1 \% \mathrm{NaNO}_{2}$ solutions at different applied potentials. He found that the difference between hold-times is small, indicating that the influence of the waveform mainly comes from the continuous deformation of the crack-tip with no effect from the hold-time. The current results agree with the observations of Wang et al., where the effect of the corrosive solution takes place on the rise and fall of the applied load and the hold-time at maximum load is not an influencing factor on CFCP rates at low temperatures. It is unlikely, that the hold-time of a trapezoidal waveform would increase the CFCP rate alloy 718 , because it is not susceptible to stress corrosion cracking under the current testing conditions. Onyewuenyi [7] tested the SCC properties for $\mathrm{U}$ bend specimens of alloy 718 with various standard aerospace heat treatments in $25 \% \mathrm{NaCl}$ at $204^{\circ} \mathrm{C}$ for six day. He found only one of three heat treatments failed under much harsher conditions than the current testing conditions.

As indicated by the polarization curves, when the temperature is increased the ionic activity is also increased. However, from the lack of difference in the crack growth rates between the different temperatures in Figure 6, there is not enough of an increase in anodic dissolution (AD) or suppression of repassivation at the crack tip to increase the CFCP rate from that of air beyond causing instability in crack growth rate. This indicates that the passivation film reformation during cyclic deformation (when the protective film is fractured and bare metal at the crack tip is exposed to the corrosive solution) is too fast to allow a significant amount of dissolution at the exposed crack tip surface before reformation of the protective film. Also, there are not enough 
chloride anions at the crack tip to slow the repassivation or weaken the newly formed film (to aid in breakdown) to effect crack growth.

It's been proven that the presence of chloride anions in the solution results in a localized acidification of the crack tip, leading to a higher dissolution rate and increased crack growth rate [28-30]. The chloride anions also slow the oxide formation reaction, allowing for more time for the crack tip surface cations to dissolve in the active region. MacDoughall [30] investigated the effect of $\mathrm{Cl}^{-}$ion on the passivation of nickel in $\mathrm{pH} 2.8 \mathrm{Na}_{2} \mathrm{SO}_{4}$ in an attempt to determine its role in initiating pitting on nickel substrates. He found that the role of $\mathrm{Cl}^{-}$is to disrupt oxide repassivation at local breakdown sites, leading to more extensive $\mathrm{Ni}^{2+}$ dissolution in the local areas. This increases the local solution acidity through hydrolysis and more rapid film breakdown through chemical dissolution. In the crack, this process is amplified due to the confined space of the crack tip and ion migration to the crack tip as a result of the increased acidity. At higher values of $\Delta \mathrm{K}$, mechanical effects become increasingly more dominant, which explains the reduced effect at $31 \mathrm{MPa} \sqrt{\mathrm{m}}$ for Specimen 0 . The effect of chloride concentration is not always seen as in the case of $3.5 \mathrm{wt} \% \mathrm{NaCl}$ solution. Ho and $\mathrm{Yu}$ [29] investigated the fatigue crack growth behavior of mill annealed Alloy 600 in $\mathrm{NaCl}$ solution at $25^{\circ} \mathrm{C}$ under different solution concentrations. They did not observe any increase in CFCP rate for increased chloride concentration, because the controlling factor was shown to be the mechanical contribution rather than the corrosiveness of the alloy. The chloride ions don't always slow the repassivation process enough for a significant amount of dissolution to occur between cycles to affect the crack growth rate. MacDoughall described it as battle between absorption of $\mathrm{Cl}^{-}$ion and the oxygen-containing species responsible for passive film formation, with the extent of $\mathrm{Cl}^{-}$ absorption increasing with its bulk concentration.

\section{Conclusion}

Based on the microstructure analysis, the average grain sizes of oil-grade alloy 718 increased from $46 \mu \mathrm{m}$ (unaged) to $52 \mu \mathrm{m}$ (one-step aged) and $60 \mu \mathrm{m}$ (two-step aged). Isolated platelet $\delta$ phases were precipitated at some of the grain boundaries in both one-step aged and two-step aged specimens. The one-step aged specimen showed a uniform distribution of fine spherical $\left(\gamma^{\prime}\right.$, in 20-30 nm diameters) and elongated $\left(\gamma^{\prime \prime}, 5-15 \mathrm{~nm}\right.$ in the c dimension and 30-150 $\mathrm{nm}$ in diameters) precipitates in the grains. On the contrary, the two-step aged sample showed much finer precipitates $\left(\gamma^{\prime}\right.$, in 2-10 nm diameters; $\gamma^{\prime \prime}, 2-12 \mathrm{~nm}$ in the c dimension and 5-35 $\mathrm{nm}$ in diameters).

Electrochemical results revealed that aging treatment has no influence on pitting corrosion resistance of oil-grade alloy 718 in all tested $\mathrm{NaCl}$ solutions. However, various $\mathrm{NaCl}$ solution conditions in terms of solution temperature and $\mathrm{NaCl}$ concentration lead to different susceptibility to pitting corrosion of oil-grade alloy 718, regardless of aging treatment. Alloy 718 exhibited passive behavior in $3.5 \mathrm{wt} . \% \mathrm{NaCl}$ solution at $\mathrm{RT}, 50^{\circ} \mathrm{C}$ and $80^{\circ} \mathrm{C}$, and the pitting corrosion resistance was decreased with increasing solution temperature. However, oil-grade alloy 718 showed an active corrosion behavior in $21 \mathrm{wt} . \% \mathrm{NaCl}$ solution at $80^{\circ} \mathrm{C}$.

CFCP results demonstrated that there is no increase in crack growth rate in a $3.5 \mathrm{wt} \% \mathrm{NaCl}$ solution for the oil-grade alloy 718 samples with different aging treatments, regardless of solution temperature. The CFCP rates of alloy 718 in $21 \mathrm{wt} \% \mathrm{NaCl}$ solution were increased in comparison with the ones tested in laboratory air and in $3.5 \mathrm{wt} \% \mathrm{NaCl}$ solution. Furthermore, 
the aging treatments led to lower CFCP rates in all tested environments. However, there was no difference of CFCP rates in $\mathrm{NaCl}$ solution between one-step aged and two-step aged specimens

The CFCP mechanism of oil-grade alloy 718 in $3.5 \mathrm{wt} \% \mathrm{NaCl}$ solution at different temperatures was dominated by mechanical variables due to the very small dissolution rate and fast repassivation kinetics at the crack tip, while both anodic dissolution and mechanical loading were controlling mechanisms for the CFCP of alloy 718 in $21 \mathrm{wt} . \% \mathrm{NaCl}$ solution at $80^{\circ} \mathrm{C}$. The higher concentration of $\mathrm{Cl}^{-}$slowed the rate of repassivation and preserved the higher dissolution rate at the crack tip, resulting in increased CFCP rate.

\section{Acknowledgement}

This research is financially supported by U.S. Department of Energy's SECA program in conjunction with National Energy Technology Laboratory's Regional University Alliance (NETL-RUA) project under contract number (DE-AC26-04NT41817).

\section{Reference}

[1] J.J. Debarbadillo and S.K. Mannan, “Alloy 718 for Oilfield Applications,” JOM, 64 (2012): pp. $265-270$

[2] J. $\mathrm{Xu}, \mathrm{H}$. John, G. Wiese and X. Liu, "Oil-Grade Alloy 718 in Oil Field Drilling Application," Superalloy 718 and Derivatives, ed. E.A. Ott et al.(Warrendale, PA: TMS, 2010): pp. 923-932.

[3] Z.F. Yin, W.Z. Zhao, W.Y. Lai and X.H. Zhao, "Electrochemical Behaviour of Ni-Base Alloys Exposed Under Oil/Gas Field Environments," Corros. Sci., 51 (2009): pp. 1702-1706.

[4] R. Ayer, R.R. Mueller, J.Y. Koo and M. Watkins, “Acceptability Criteria for Alloy 718 for Use in Sour Service," (Paper presented at The Thirteenth International Offshore and Polar Engineering Conference, Honolulu, Hawaii, 25-30 May 2003): pp. 75-82.

[5] R.B. Bhavsar, A. Collins, and S. Silverman, "Use of Alloy 718 and 725 in Oil and Gas Industry," Superalloys 718, 625, 706 and Various Derivatives, ed. E.A. Loria (Warrendale, PA: TMS, 2001): pp. 47-55.

[6] J. Kolts, "Alloy 718 for the Oil and Gas Industry," Superalloy 718-Metallurgy and Applications, ed, E.A. Loria (Warrendale, PA: TMS, 1989): pp. 329-344.

[7] O.A. Onyewuenyi, "Alloy 718-Alloy Optimization for Applications in Oil and Gas Production," Superalloy 718-Metallurgy and Applications, ed. E.A. Loria (Warrendale, PA: TMS, 1989): pp. 345-362.

[8] API Standard 6A718, Specification of Nickel Base Alloy 718 (UNS N07718) for Oil and Gas Drilling and Production Equipment, American Petroleum Institute 2004.

[9] Aerospace Material Specification 5662M, Nickel Alloy, Corrosion and Heat-Resistant, Bars, Forgings, and Rings, SAE International 2004. 
[10] NACE Standard MR0175-2003, Standard Materials Requirements: Metal for Sulfide Stress Cracking and Stress Corrosion Cracking Resistance in Sour Oilfield Environments, NACE International 2003.

[11] T. Chen, H. John, J. Xu, Q. Lu, J. Hawk and X. Liu, "Influence of Surface Modifications on Pitting Corrosion Behavior of Nickel-Base Alloy 718. Part 2: Effect of Aging Treatment," Corros. Sci., 78 (2014): pp. 151-161.

[12] X. Liu, J. Xu, E. Barbero, W. Cao and R. Kennedy, "Effect of Thermal Treatment on the Fatigue Crack Propagation Behavior of a New Ni-Base Superalloy," Mater. Sci. Eng. A, 474 (2008): pp. 30-38.

[13] L.A. James, and W.J. Mills, "Effect of Heat-Treatment and Heat-To-Heat Variations in the Fatigue-Crack Growth Response of Alloy 718". Engineering Fracture Mechanics, 1985. 22(5): pp. 797-817

[14] L.A. James and W.J. Mills, "Effect of Heat Treatment Upon Fatigue Crack GrowthBehavior of Alloy 718 Weldments. 1. Macroscopic Behavior". Journal of Engineering Materials and Technology-Transactions of the Asme, 1985. 107(1): pp. 34-40.

[15] W.J. Mills and L.A. James, Effect of Heat Treatment upon Fatigue Crack Growth-Behavior of Alloy 718 Weldments. 2. Microscopic Behavior. Journal of Engineering Materials and Technology-Transactions of the Asme, 1985. 107(1): pp. 41-47.

[16] J.L. do Nascimento, C. Barbosa, and J.L. Fernandes, "Effect of Different Heat Treatment Conditions on the Microstructure and Mechanical Properties of Inconel 718 Nickel Based Super Alloy Used in Petroleum Production". Praktische Metallographie-Practical Metallography, 2009. 46(12): pp. 640-656.

[17] G.A. Rao, M. Kumar, M. Srinivas and D.S. Sarma, "Effect of Standard Heat Treatment on the Microstructure and Mechanical Properties of Hot Isostatically Pressed Superalloy Inconel 718". Materials Science and Engineering: A, 2003. 355(1-2): pp. 114-125.

[18] G. Yu, C.Wang, J. Huang, "The Effects Of Heat Treatment And Hydrogen On The SCC Behavior Of Superalloy 718", in NACE CORROSION 1996. 1996: Houston.

[19] J.M. Pereira and B.A. Lerch, "Effects of Heat Treatment on the Ballistic Impact Properties of Inconel 718 for Jet Engine Fan Containment Applications". International Journal of Impact Engineering, 2001. 25(8): pp. 715-733.

[20] J. Deleume, J.-M. Cloué, and E. Andrieu, "Influence of $\Delta$ Phase Precipitation on the Stress Corrosion Cracking Resistance of Alloy 718 in PWR Primary Water". Journal of Nuclear Materials, 2008. 382(1): pp. 70-75.

[21] S. Ghosh, S. Yadav, and G. Das, "Study of Standard Heat Treatment on Mechanical Properties of Inconel 718 Using Ball Indentation Technique". Materials Letters, 2008. 62(1718): pp. 2619-2622.

[22] L.W. Tsay, H.H. Lin, and R.K. Shiue, "Fatigue Crack Growth Behavior of Laser-Annealed IN 718 Alloy in Hydrogen”. Corrosion Science, 2004. 46(11): pp. 2651-2662.

[23] M. Clavel and A. Pineau, "Fatigue Behavior of 2 Nickel-base Alloys.1. Experimental Results on Low-cycle Fatigue, Fatigue Crack-Propogation and Substructures". Materials Science and Engineering, 1982. 55(2): pp. 157-171. 
[24] M. Sundararaman, P. Mukhopadhyay, and S. Banerjee, "Deformation-Behavior of Gamma" Strengthened INCONEL-718". Acta Metallurgica, 1988. 36(4): p. 847-864.

[25] D.F. Paulonis, J.M. Oblak, and D.S. Duvall, "Precipitation in Nickel-Base Alloys 718". Asm Transactions Quarterly, 1969. 62(3): pp. 611-622.

[26] C. Mercer, A.B.O. Soboyejo, and W.O. Soboyejo, "Micromechanisms of Fatigue Crack Growth in a Forged Inconel 718 Nickel-Based Superalloy". Materials Science and Engineering $a$-Structural Materials Properties Microstructure and Processing, 1999. 270(2): pp. 308-322.

[27] Z.F. Wang, J. Li, J.Q. Wang and W. Ke, "The Influence of Loading Waveform on Corrosion Fatigue Crack Propagation," Corros. Sci., 37 (1995): pp. 1551-1565.

[28] K. R. Cooper and R. G. Kelly, "Using Capillary Electrophoresis to Study the Chemical Conditions Within Cracks in Aluminum Alloys," Journal of Chromatography A, 850 (1999): pp. 381-389.

[29] J. T. Ho and G. P. Yu, "Fatigue Behavior of Alloy-600 in $\mathrm{NaCl}$ Solution at Room Temperature," Journal of Nuclear Materials, 226 (1995): pp. 226-237.

[30] B. MacDougall, "Effect of Chloride-ion on the Localized Breakdown of Nickel-Oxide Films," Journal of The Electrochemical Society, 126 (1979): pp. 919-925.

[31] H. Ghonem, T. Nicholas, A. Pineau, "Elevated temperature fatigue crack growth in alloy 718 - Part I: Effects of mechanical variables". Fatig. Fract. Eng. Mater. Struct. 16 (1993): pp. 565-576.

[32] H. Ghonem, T. Nicholas, A. Pineau, "Elevated temperature fatigue crack growth in alloy 718 - Part II: Effects of environmental and material variables". Fatig. Fract. Eng. Mater. Struct. 16 (1993): pp. 577-590. 